\title{
Diagnostic reference levels for the most frequent radiological examinations carried out in Brazil
}

\author{
Marcelo B. Freitas ${ }^{1}$ and Elisabeth M. Yoshimura ${ }^{2}$
}

Suggested citation Freitas MB, Yoshimura EM. Diagnostic reference levels for the most frequent radiological examinations carried out in Brazil. Rev Panam Salud Publica. 2009;25(2):95-104.

ABSTRACT Objectives. A large-scale survey of doses to patients undergoing the most frequent radiological examinations was carried out in health services in São Paulo (347 radiological examinations per 1000 inhabitants), the most populous Brazilian state.

Methods. A postal dosimetric kit with thermoluminescence dosimeters was used to evaluate the entrance surface dose (ESD) to patients. A stratified sampling technique applied to the national health database furnished important data on the distribution of equipment and the annual number of examinations. Chest, head (skull and sinus), and spine (cervical, thoracic, and lumbar) examinations were included in the trial. A total of 83 rooms and 868 patients were included, and 1415 values of ESD were measured.

Results. The data show large coefficients of variation in tube charge, giving rise to large variations in ESD values. Also, a series of high ESD values associated with unnecessary localizing fluoroscopy were detected. Diagnostic reference levels were determined, based on the 75 th percentile (third quartile) of the ESD distributions. For adult patients, the diagnostic reference levels achieved are very similar to those obtained in international surveys. However, the situation is different for pediatric patients: the ESD values found in this survey are twice as large as the international recommendations for chest radiographs of children.

Conclusions. Despite the reduced number of ESD values and rooms for the pediatric patient group, it is recommended that practices in chest examinations be revised and that specific national reference doses and image quality be established after a broader survey is carried out.

Key words Thermoluminescent dosimetry, radiology, Brazil.

The radiation protection system for patients subjected to medical exposures

Instituto de Física Gleb Wataghin (IFGW), Universidade Estadual de Campinas-UNICAMP, Departamento de Física Aplicada, Cidade Universitária Zeferino Vaz, 13083-970, Campinas, Brazil. Send correspondence and reprint requests to: Marcelo Freitas, Instituto de Física Gleb Wataghin, IFGW / UNICAMP, Departamento de Física Aplicada, Cidade Universitária Zeferino Vaz, 13083-970, Campinas, Brazil; telephone: 5519 35215333; fax: 5519 53215343; e-mail: mfreitas@ifi.unicamp.br

2 Departamento de Física Nuclear, Instituto de Física, Universidade de São Paulo, P.O. Box 66318, 05315-970, São Paulo, SP, Brazil. in diagnostic radiology is governed by principles of justification and optimization, including the consideration of diagnostic reference levels (DRLs). Therefore, a diagnostic radiological procedure is justified if the benefits to the individual patient from the medical diagnostic obtained with the radiological image balance the individual detriment the exposure may cause. Once a medical exposure has been justified, the principle of optimization is applied-that is, the radiological examination must be carried out with equipment and exposure parameters that ensure doses to patients as low as reasonably practicable, consistent with the intended diagnostic purpose (1). For diagnostic medical exposures, this value is interpreted as being the lowest dose possible, which is consistent with the required image quality that is necessary for obtaining the desired diagnostic information.

From these principles, and considering that all medical exposures bring a potential health benefit to patients, dose 
limits for radiological examinations have not been established, in contrast to occupational and public exposure restrictions. Substituting for dose limits, DRLs are used in diagnostic radiology: dose levels in medical radiodiagnostic practices for typical examinations for groups of standard-sized patients or standard phantoms for broadly defined types of equipment. These levels are expected not to be exceeded for standard procedures when good and normal practice regarding diagnostic and technical performance is applied (2). However, exceeding this level does not automatically mean an examination is inadequately performed, and meeting this level does not automatically equate with good practice, as the image quality may be poor. The goal is clearly to use DRLs to control the level of optimization of the procedures.

The United States (1988) and the United Kingdom (1992) were the first to adopt DRLs for patients' medical exposures (3). After these national initiatives, international recommendations from societies for radiological protection were published. The International Commission on Radiological Protection (4) suggests the use of investigation levels for medical exposures as a starting point in the identification of incorrect practices. In addition, in Publication 73 (5), the Commission recommends that DRLs be used to optimize patient doses. They can serve as a quality assurance tool for diagnostic radiology, providing a trigger for local review, if consistently exceeded.

In Europe, dose values associated with DRLs were published in a set of three recommendations: European Guidelines on Quality Criteria for Diagnostic Radiographic Images in adult (6) and pediatric (7) patients and for computed tomography in adult patients (8). These publications recommended using the third-quartile values (75th percentile) of the distribution of mean doses observed for a particular examination to establish national DRLs. The distribution of mean doses was obtained on large-scale surveys carried out in representative samples of health services distributed in some European countries.

In Brazil, DRLs in medical radiology were established by regulation of the Brazilian Ministry of Health in 1998, through Portaria number 453 (9). Although not mentioned in the document, the national regulation adopts the same
DRL values published by the International Atomic Energy Agency in Safety Series number 115 (10). It is important to point out that reference levels must be established considering the national or regional reality and taking into account the equipment and human resources available.

Therefore, considering the need to establish DRLs based on national reality and also the lack of large-scale dose surveys in Brazil, this study provides a survey of entrance surface dose (ESD) values delivered to patients subjected to the most frequent radiological examinations: chest, skull, sinus, and spine (cervical, thoracic, and lumbar), carried out in a representative sample of clinics and hospitals in the most populous Brazilian state, São Paulo (39.2 million inhabitants in $2004,22 \%$ of the country's population). DRLs are inferred from a distribution of mean ESD values to standard-sized patients for each type of radiograph considered. Furthermore, information about the health services (distribution of equipment and annual number of radiological examinations) and about the exposure parameters used in the examinations (tube potential in kilovolts $(\mathrm{kV})$, exposure setting in milliampere-seconds (mAs), source-image distance) are also analyzed, allowing an overview of the medical exposures in Brazil, specifically in the state of São Paulo.

\section{MATERIALS AND METHODS}

\section{Health services and postal dosimetric kit}

Private and public hospitals and clinics in the state of São Paulo were randomly selected by a stratified sampling technique (11) from a national database supported by the Brazilian Ministry of Health (12). The number of radiological examinations carried out annually in the cities of the state and the distribution of conventional x-ray equipment were used in the sampling process. Details about this information were previously published (13). A total of 200 of the existing 1440 health services were sampled.

Postal dosimetric kits to evaluate the quantity of ESD to patients subjected to the most frequent radiological examinations were sent to health services that agreed to cooperate. In the first postal delivery (D1), ESDs to patients subjected to chest exams (posteroanterior (PA), an- teroposterior (AP), and lateral (LAT) projections) were evaluated (14). After the kits were returned to the laboratory to register the supplied information and evaluate the doses, a second postal delivery (D2) was sent-this time for evaluation of ESDs to patients subjected to skull (PA, AP, and LAT projections); sinus (Waters and Caldwell projections); and cervical, thoracic, and lumbar spine (PA, AP, and LAT projections) examinations.

The initial design of the kit was based on a protocol established by the National Radiological Protection Board (15), a product of the experience acquired from similar studies in the United Kingdom. Adjustments were made, considering national reality - that is, material and financial resources available, institutions and personnel involved, and sample size.

Each dosimetric kit comprises a number of thermoluminescence dosimeters (TLD-100), enough to evaluate doses to approximately 10 patients, detailed instructions, and a set of forms for recording patient, equipment, radiographic technique (exposure parameters), and health service data. Two nonirradiated TLDs were also included in the kit to evaluate the contribution of background radiation, to be subtracted from the results of the group. During the examination, the radiological technician attached one pair of packed TLDs directly to the patient's skin at a point close to the center of the incident x-ray beam and completed the forms with the requested data. Specific instructions pointed out that the dosimeters used in the examinations would be considered for evaluation of the doses only when the images showed the diagnostic information as required by the radiologist. All material was sent to the participant health services and returned to the laboratory for analysis by special postal delivery, prepaid by our laboratory. All information collected during the study about health services, examinations, and patients was stored on specific spreadsheets for analysis.

\section{Dosimetry and classification of patients}

The quantity measured in this survey was ESD: absorbed dose to soft tissue at the point of intersection of the beam axis with the patient surface (skin), including backscattered radiation. The system was calibrated with a group of TLDs irradi- 
ated to known doses in air, with x-rays (tube voltage of $100 \mathrm{kV}$, added filtration of $4 \mathrm{mmAl}$, equivalent energy of 38 kiloelectronvolts). The calibration was repeated for each batch of TLDs prepared for measurement. The calibration doses (from 0.2 to 2.0 milligrays (mGy)) were measured using a 6-cubic-centimeter ion chamber with a Radcal monitor (model 9015). The background radiation contribution was evaluated and subtracted from the calibration curve. The TLD reader used in the measurements of thermoluminescence intensity was developed in our laboratory. DRLs were determined through the 3rd quartile of the distribution of mean ESD values.

Mean ESD to patients in each room (or x-ray equipment) for each radiograph type was calculated from individual ESD values received by two selected groups of patients: one less than 15 years old (pediatric) and the other older than 15 years and weighing between 50 and 90 kilograms (kg) (standard-sized adult). The clear categorization of standard patients (pediatric and adult) is an important procedure to evaluate the DRLs, and, as no request was made to health service staff about the selection of patients by sex, age, weight, or height, it had to be done in the analysis process. This procedure allows for comparison between ESD values of different health services. In the case of pediatric patients, the physical characteristics change quickly with age, and patient subgroups are usually defined for evaluation of the pediatric DRLs. As this procedure would decrease even more the sample of ESDs to pediatric patients, the values associated with the 3rd quartile of the ESD distribution of the whole group (less than 15 years old) were considered an indication of the pediatric patient DRLs. In this way, we believe our results can contribute for a first analysis of this age group of patients in Brazil.

\section{RESULTS AND DISCUSSION}

\section{Equipment and examination surveys}

In 2004, the health services localized in the state of São Paulo comprised a total of 243.9 pieces of diagnostic imaging equipment per million population. Among them, x-ray equipment used in conventional radiological examinations (chest, skull, spine) accounts for 35\% (85.4 per million). In the case of $x$-ray equipment used for mammography, 30.7 pieces of equipment per million population are registered. As expected, a significant decrease in the amount of equipment is observed when technologically more sophisticated equipment is concerned: magnetic resonance (2.9 per million), gamma cameras (3.3 per million), and computed tomography (11.2 per million).

The annual number of radiological examinations per 1000 population in São Paulo state-347.0 - means that, on average, one in three inhabitants is subjected to a radiological examination at least once per year, considering only clinical procedures in outpatients carried out in the health services associated with the Brazilian Health Public System (Sistema Único de Saúde, SUS). Radiological examinations of the chest, head (skull and sinus), and spine show the largest annual frequencies: 110, 47, and 32 per 1000 population (2004), respectively. The relative contribution of each type of examination to the total frequency is shown in Figure 1. The choice of the radiological examinations to be included in the evaluation of ESDs was based on the frequencies shown there.

Chest, head (skull and sinus), and spine examinations make up more than half the annual amount of conventional radiological examinations carried out in São Paulo state. As x-ray examinations of the extremities (arm, hand, leg, etc.) have little importance from the point of view of radiation protection, considering the region

FIGURE 1. Percent contribution of each type of radiological examination carried out in health services of São Paulo state, Brazil, 2004

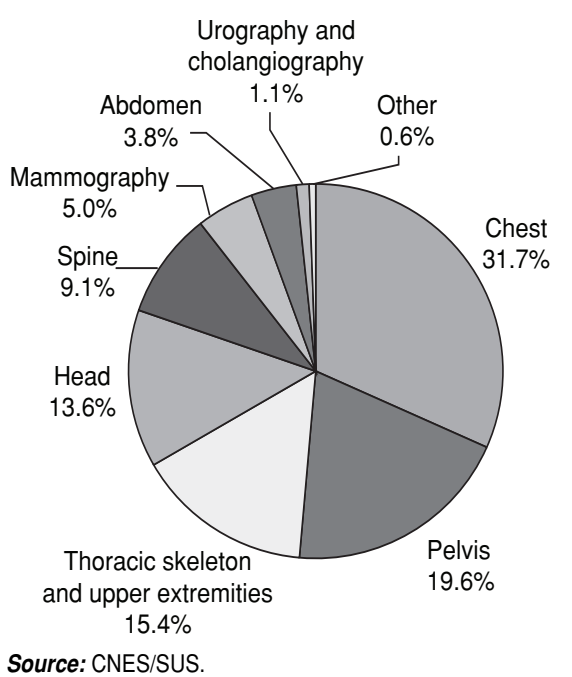

of the body that is irradiated, they were not included in this survey, although they are performed very frequently.

\section{Sample size of the health services}

A sample of 200 health services facilities were invited to participate in this study; 50 of them agreed to participate and received the first postal delivery (D1) with dosimetric kits to evaluate ESDs in chest examinations. In the second postal delivery (D2), 38 of them remained in the study and participated in the evaluation of ESDs to skull, sinus, and spine examinations. Different categories of health services were included: 32 are private and 18 are public (federal, state, and municipal), with a variety of magnitudes and levels of health care (general and specialized hospitals, treatment centers, primary and specialist care, among others). The number of health services facilities participating in the study is probably an indication that there still is neither tradition nor appraisal in performing similar surveys in the country.

This hypothesis is corroborated by the first surveys conducted in the United Kingdom in the 1980s (16), which reached a small sample with about 20 medical facilities. The first survey conducted in the European Union in 1987 and 1988 involved 24 radiology departments distributed in 10 European countries (6). Despite the small number of participant health services, we believe this study can contribute to any future large-scale dose survey in the sense that it intends to demonstrate the importance of the process of evaluation of doses in diagnostic radiology.

\section{Selection and analysis of data}

A total of 83 rooms (or x-ray equipment) and 868 patients were included in this study, and a set of 1415 values of ESD were measured.

A comparison of the relative age distribution of the population of São Paulo state (2004) with the patients included in this study, for each examination type, is shown in Figure 2. In contrast to the whole population, the age distribution of patients subjected to chest and spine examinations peaked in the age range from 30 to 60 years. The age distribution of patients subjected to skull and sinus procedures is predominantly younger, less than 20 years old, more similar to the 
FIGURE 2. Relative age distribution of population of São Paulo state compared with patients included in this study for each examination type, Brazil, 2004

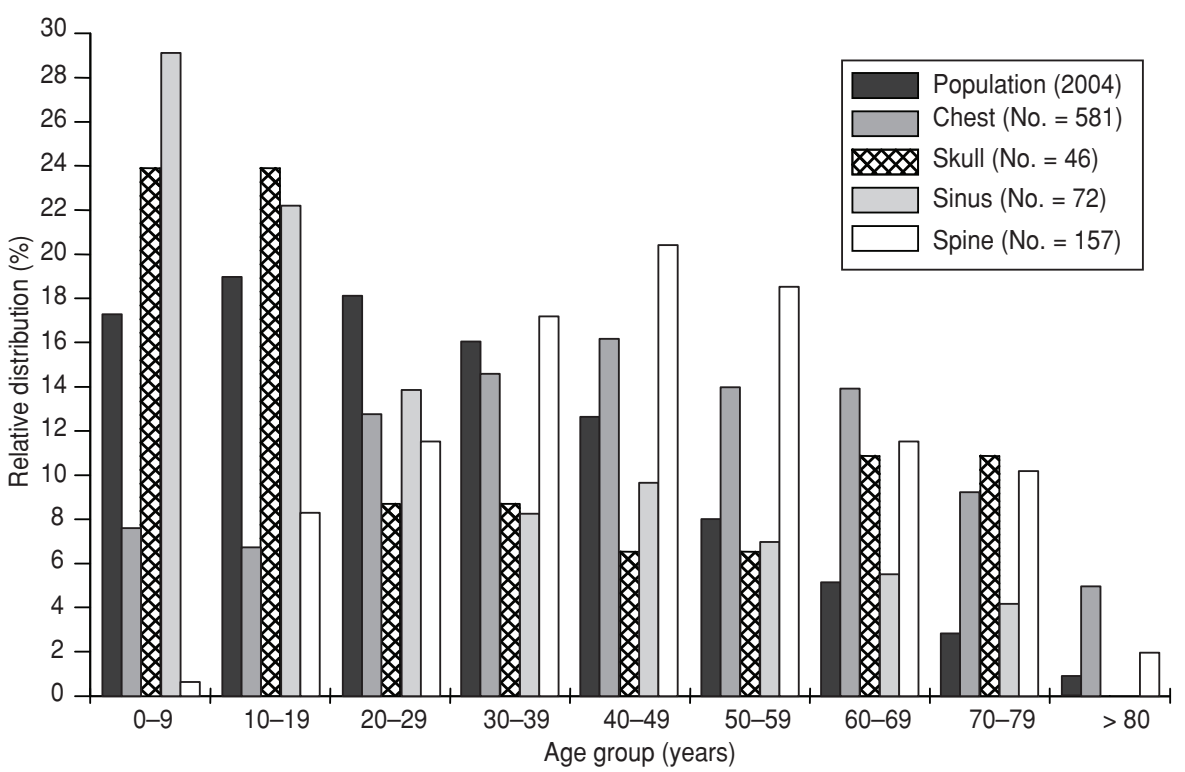

Source: The Brazilian Institute of Geography and Statistics (IBGE) 2004.

population distribution, but with a higher relative percentage in the younger age group. In the specific case of skull examinations, there are a significant number of examinations in the age group between 60 and 80 years. Concerning gender distribution, similar percentages of male and female patients are subjected to chest examinations, but there is a predominance of men subjected to skull and sinus examinations (53\%) and of women subjected to spine examinations $(57 \%)$.

The number of rooms and health services participating in this study and the number of ESD values measured for different examinations and projections are shown in Table 1 . A set of 1415 ESD values were measured, and among them the values corresponding to standard patients were selected for comparative analysis of the exposure parameters and determination of the DRLs: adult (1 074) and pediatric (194). This selection led to a reduction of about $10 \%$ in the number of ESDs analyzed and about $24 \%$ when only standard adult patients are considered (patient weight between 50 and 90 $\mathrm{kg}$ and older than 15 years).

Analysis of the projections for each examination shows that the least frequent projection was the PA, except for chest examination. AP chest projections are most frequent when pediatric patients are considered. Lumbar spine is the most frequently examined spine region.

As this study was not directed at the pediatric patient group (less than 15 years old), the number of ESD values in this group is reduced, although the number of ESDs to chest and sinus examinations is still considerable. The analyses of this study are therefore concentrated in the most frequent examinations (and projections): chest (AP, PA, and LAT projections); skull (AP and LAT projections); sinus (Waters and Caldwell projections); and cervical, thoracic, and lumbar spine (AP and LAT projections) only to adult patients.

\section{Diagnostic reference levels}

Technical parameters. Descriptive statistics (mean, minimum, and maximum values and coefficient of variation $(\mathrm{CV})$ ) related

TABLE 1. Quantities of collected data ${ }^{a}$ during all studies for different radiological examinations, Brazil, 2004

\begin{tabular}{|c|c|c|c|c|c|c|c|c|c|}
\hline \multirow[b]{2}{*}{ Examination $^{b}$} & \multicolumn{3}{|c|}{ Collected data, all } & \multicolumn{3}{|c|}{ Selected data, adultc } & \multicolumn{3}{|c|}{ Selected data, pediatric ${ }^{d}$} \\
\hline & Health services & Rooms & $\mathrm{ESD}^{\mathrm{e}}$ (No.) & Health services & Rooms & $\mathrm{ESD}^{\mathrm{e}}$ (No.) & Health services & Rooms & $\mathrm{ESD}^{\mathrm{e}}$ (No.) \\
\hline AP chest & 22 & 25 & 89 & 13 & 16 & 48 & 14 & 14 & 33 \\
\hline PA chest & 45 & 69 & 490 & 45 & 68 & 399 & 13 & 15 & 26 \\
\hline LAT chest & 45 & 67 & 302 & 42 & 63 & 231 & 13 & 14 & 33 \\
\hline AP skull & 22 & 27 & 36 & 14 & 17 & 20 & 12 & 14 & 15 \\
\hline LAT skull & 23 & 27 & 44 & 14 & 17 & 27 & 13 & 14 & 15 \\
\hline PA skull & 5 & 5 & 11 & 3 & 3 & 9 & 2 & 2 & 2 \\
\hline Waters sinus & 24 & 35 & 75 & 21 & 27 & 43 & 15 & 17 & 28 \\
\hline Caldwell sinus & 23 & 32 & 65 & 20 & 25 & 37 & 15 & 16 & 24 \\
\hline AP lumbar spine & 26 & 37 & 102 & 25 & 33 & 91 & 4 & 4 & 5 \\
\hline LAT lumbar spine & 29 & 40 & 112 & 27 & 35 & 97 & 4 & 4 & 5 \\
\hline PA lumbar spine & 4 & 4 & 12 & 3 & 3 & 8 & 0 & 0 & 0 \\
\hline AP cervical spine & 12 & 12 & 18 & 11 & 11 & 17 & 1 & 1 & 1 \\
\hline LAT cervical spine & 16 & 16 & 23 & 15 & 15 & 21 & 1 & 1 & 1 \\
\hline PA cervical spine & 3 & 3 & 4 & 3 & 3 & 3 & 0 & 0 & 0 \\
\hline AP thoracic spine & 12 & 13 & 15 & 9 & 10 & 11 & 3 & 4 & 4 \\
\hline LAT thoracic spine & 13 & 13 & 15 & 10 & 10 & 11 & 2 & 2 & 2 \\
\hline PA thoracic spine & 1 & 1 & 2 & 1 & 1 & 1 & 0 & 0 & 0 \\
\hline Total & & & 1415 & & & 1074 & & & 194 \\
\hline
\end{tabular}

a From these data, those corresponding to standard-sized adult and pediatric patients were selected.

${ }^{\mathrm{b}} \mathrm{AP}$, anteroposterior; PA, posteroanterior; LAT, lateral.

${ }^{c}$ Adult patients older than 15 years and weighing between 50 and $90 \mathrm{~kg}$.

d Pediatric patients up to 15 years old.

e ESD, entrance surface dose. 
TABLE 2. Mean values of tube potential, exposure setting, and source-image distance (SID) for each type of radiological examination carried out in standard-sized adult patients, Brazil, 2004

\begin{tabular}{|c|c|c|c|}
\hline \multirow[b]{2}{*}{ Examination ${ }^{a}$} & \multicolumn{3}{|c|}{ Selected data, adult ${ }^{b}$} \\
\hline & Tube potential, kV & Exposure setting, mAs & SID, meters \\
\hline AP chest & $66(21 \%)^{c}[40-90]^{d}$ & 17 (65\%) [5-40] & $1.60(16 \%)[0.80-1.80]$ \\
\hline PA chest & 77 (18\%) [54-125] & $12(83 \%)[1-80]$ & $1.70(15 \%)[1.00-2.00]$ \\
\hline LAT chest & $87(15 \%)$ [60-125] & $20(80 \%)[1-150]$ & $1.70(12 \%)[0.80-2.00]$ \\
\hline AP skull & $66(9 \%) \quad[52-77]$ & 59 (76\%) [20-200] & $1.05(5 \%) \quad[1.00-1.15]$ \\
\hline LAT skull & $60(12 \%) \quad[40-70]$ & $74(89 \%)$ [10-200] & $1.05(9 \%) \quad[1.00-1.40]$ \\
\hline Waters sinus & $74(12 \%)$ [55-100] & $45(35 \%)$ [15-80] & $0.95(26 \%)[0.60-1.15]$ \\
\hline Caldwell sinus & $71(11 \%)$ [50-90] & 45 (38\%) [25-80] & $0.95(26 \%)[0.60-1.15]$ \\
\hline AP lumbar spine & $70(11 \%)$ [52-96] & $84(69 \%)$ [20-250] & $1.05(14 \%)[0.80-1.80]$ \\
\hline LAT lumbar spine & $81(14 \%)$ [57-125] & 147 (82\%) [25-600] & $1.05(14 \%)[0.80-1.80]$ \\
\hline AP cervical spine & $64(8 \%) \quad[56-75]$ & 25 (60\%) [8-51] & $1.05(19 \%)[1.00-1.50]$ \\
\hline LAT cervical spine & $66(9 \%) \quad[58-78]$ & 27 (59\%) [6-63] & $1.05(19 \%)[0.80-1.50]$ \\
\hline AP thoracic spine & $69(10 \%)$ [56-80] & $36(50 \%)$ [10-70] & $1.05(5 \%) \quad[1.00-1.15]$ \\
\hline LAT thoracic spine & $73(12 \%)$ [63-92] & $56(68 \%)$ [16-125] & $1.05(5 \%) \quad[1.00-1.15]$ \\
\hline
\end{tabular}

${ }^{a} \mathrm{AP}$, anteroposterior; PA, posteroanterior; LAT, lateral.

${ }^{\mathrm{b}}$ Adult patients above 15 years old and weighing between 50 and $90 \mathrm{~kg}$

${ }^{c}$ Coefficients of variation are shown in parentheses.

${ }^{\mathrm{d}}$ Ranges (minimum and maximum values) are shown in brackets.

TABLE 3. Mean values of tube potential, exposure setting, and source-image distance (SID) for each type of radiological examination carried out in pediatric patients, Brazil, 2004

\begin{tabular}{|c|c|c|c|}
\hline \multirow[b]{2}{*}{ Examination ${ }^{a}$} & \multicolumn{3}{|c|}{ Selected data, pediatric ${ }^{b}$} \\
\hline & Tube potential, kV & Exposure setting, mAs & SID, meters \\
\hline AP chest & $61(15 \%)^{c}[42-75]^{d}$ & $9(55 \%) \quad[3-15]$ & $1.25(24 \%)[0.80-1.80]$ \\
\hline PA chest & $71(17 \%)$ [50-104] & $11(154 \%)$ [4-80] & $1.75(14 \%)[1.00-2.00]$ \\
\hline LAT chest & 75 (15\%) [50-94] & $14(71 \%) \quad[4-48]$ & $1.50(20 \%)[0.80-1.80]$ \\
\hline AP skull & $65(12 \%)[50-75]$ & $23(56 \%) \quad[5-50]$ & $1.00(5 \%) \quad[1.00-1.10]$ \\
\hline LAT skull & $61(13 \%)[50-80]$ & $21(71 \%) \quad[4-50]$ & $1.00(5 \%) \quad[1.00-1.10]$ \\
\hline Waters sinus & $69(7 \%) \quad[60-77]$ & $40(50 \%)$ [20-90] & $1.00(20 \%)[0.80-1.30]$ \\
\hline Caldwell sinus & $67(7 \%) \quad[60-75]$ & $40(55 \%) \quad[15-90]$ & $1.00(20 \%)[0.80-1.30]$ \\
\hline
\end{tabular}

a AP, anteroposterior; PA, posteroanterior; LAT, lateral.

b Pediatric patients up to 15 years old.

${ }^{c}$ Coefficients of variation are shown in parentheses.

${ }^{\mathrm{d}}$ Ranges (minimum and maximum values) are shown in brackets.

to the exposure parameters $(\mathrm{kV}, \mathrm{mAs}$, and source-image distance) are shown in Table 2 (adult patients) and Table 3 (pediatric patients). Broad variations were observed for the exposure setting (mAs), as the CV values demonstrate. The tube potential $(\mathrm{kV})$ values used in examinations of adult patients obtained in this study are very similar to those in a previous survey carried out in the United Kingdom between 1988 and 1995 (17). On the other hand, the exposure settings (mAs) reported here are, in some cases, almost twice as large as the European ones. This fact may indicate that there are some technical limitations, such as low output of the x-ray tubes sampled in this study. In another survey conducted in many countries of the European Union (6), after publication of quality criteria for diagnostic radiology, tube potential $(\mathrm{kV})$ values were significantly higher than the ones reported in this study. For PA and LAT chest examinations, approximately $85 \%$ of departments in the European trial indicated that they used tube potential above $100 \mathrm{kV}$, whereas in this study only $7 \%$ of all health services complied with that practice. With regard to lumbar spine examinations, the situation is not very different: values for $\mathrm{AP} / \mathrm{PA}$ projections ranged from 70 to $90 \mathrm{kV}$ in $70 \%$ of the examinations in the European trial, and in this study, $50 \%$ of AP lumbar spine examinations used a tube potential higher than $70 \mathrm{kV}$.

Analyzing exposure parameters for pediatric patients was difficult, because the physical characteristics of the patients vary significantly, and age is not enough to characterize them. As a result, the technical parameters used in the examinations have no regularity, as shown in Table 3. Two smaller-scale sur- veys of doses to pediatric patients (less than 15 years old) undergoing chest examinations (AP and PA projections) carried out in Brazil-in Pernambuco (18) and in Rio de Janeiro (19) states-obtained mean tube potential values between 65 and $75 \mathrm{kV}$ and exposure settings between 2.5 and 15 mAs, both intervals much narrower than what we found. A dose survey of pediatric patients in countries of the European Union (7) showed that approximately $80 \%$ of chest examinations (AP and PA projections) in children with a mean age of 5 years used tube potentials more than $60 \mathrm{kV}$, whereas in this study the practice corresponds to $55 \%$ of the examinations.

Entrance surface dose. Mean ESDs per room or x-ray equipment were calculated from individual ESDs measured to selected patients undergoing the examination considered. With this procedure, the final estimate of ESD for the examination considered is independent of the number of ESDs measured for each room. Descriptive statistics (mean, median, and third quartiles) of mean ESD per room for each examination are shown in Table 4 (adult) and Table 5 (pediatric). The ratio of maximum to minimum ESD values varies enormously, reaching 1:195 and 1:114 in sinus examinations of adult and pediatric patients, respectively. For PA chest examinations of pediatric and adult patients, there is a remarkable unexpected similarity between the mean ESD values (0.22 and $0.30 \mathrm{mGy}$, respectively).

Although the methodology used in previous national studies is not completely similar to the one used in this study, and large-scale dose surveys in Brazil are still not available, it is possible to compare our results with the ESD values published in the literature. Dose surveys conducted in two Brazilian cities (Curitiba (20) and São Paulo (21)) reported mean ESD values to adult patients undergoing chest examinations similar to the ones obtained here: 0.33 and $0.22 \mathrm{mGy}$ (PA projection) and 1.01 and $0.98 \mathrm{mGy}$ (LAT projection). Mean ESD values to pediatric patients were reported between 0.22 and $0.28 \mathrm{mGy}$, depending on the age, in chest examinations (AP and PA projections) carried out in the city of Recife (18). Another study of doses to pediatric patients conducted in Rio de Janeiro (19) reported 
TABLE 4. Descriptive statistics (mean, median, and third quartiles) of mean entrance surface dose (ESD) per room for each examination carried out in standard-sized adult patients; number of individual ESD values and rooms included in calculation of mean ESD also shown, Brazil, 2004

\begin{tabular}{|c|c|c|c|c|c|}
\hline \multirow[b]{2}{*}{ Examinationa } & \multicolumn{3}{|c|}{$\mathrm{ESD}_{\text {mean }}, \mathrm{mGy}$} & \multirow[b]{2}{*}{ ESD (No.) } & \multirow[b]{2}{*}{ Rooms } \\
\hline & Mean & Median & Third quartile & & \\
\hline AP chest & 0.40 & 0.32 & 0.50 & 48 & 16 \\
\hline PA chest & 0.30 & 0.25 & 0.35 & 399 & 68 \\
\hline LAT chest & 0.87 & 0.69 & 0.96 & 231 & 63 \\
\hline AP skull & 2.80 & 2.12 & 3.28 & 20 & 17 \\
\hline LAT skull & 2.04 & 1.53 & 2.14 & 27 & 17 \\
\hline Waters sinus & 2.11 & 2.09 & 2.80 & 43 & 27 \\
\hline Caldwell sinus & 2.02 & 2.14 & 2.69 & 37 & 25 \\
\hline AP lumbar spine & 5.4 & 4.6 & 6.6 & 91 & 33 \\
\hline LAT lumbar spine & 11.2 & 8.6 & 16.2 & 97 & 35 \\
\hline AP cervical spine & 0.52 & 0.49 & 0.72 & 17 & 11 \\
\hline LAT cervical spine & 0.77 & 0.49 & 1.20 & 21 & 15 \\
\hline AP thoracic spine & 2.16 & 1.96 & 2.91 & 11 & 10 \\
\hline LAT thoracic spine & 4.87 & 2.99 & 6.24 & 11 & 10 \\
\hline
\end{tabular}

${ }^{a} \mathrm{AP}$, anteroposterior; PA, posteroanterior; LAT, lateral.

TABLE 5. Descriptive statistics (mean, median, and third quartiles) of mean entrance surface dose (ESD) per room for each examination carried out in pediatric patients; number of individual ESD values and rooms included in calculation of mean ESD also shown, Brazil, 2004

\begin{tabular}{lcccccc}
\hline \multirow{2}{*}{ Examinationa } & \multicolumn{3}{c}{ ESD $_{\text {mean }}$, mGy } & & & \\
\cline { 2 - 4 } & Mean & Median & Third quartile & ESD (No.) & Rooms & DRLs, ${ }^{\text {b }}$ mGy \\
\hline AP chest & 0.15 & 0.13 & 0.20 & 33 & 14 & 0.10 \\
PA chest & 0.22 & 0.15 & 0.35 & 26 & 15 & 0.10 \\
LAT chest & 0.44 & 0.36 & 0.56 & 33 & 14 & 0.20 \\
AP skull & 0.90 & 0.96 & 1.06 & 15 & 14 & 1.50 \\
LAT skull & 0.74 & 0.62 & 0.83 & 15 & 14 & 1.00 \\
Waters sinus & 1.36 & 1.31 & 2.01 & 28 & 17 & - \\
Caldwell sinus & 1.30 & 1.21 & 1.98 & 24 & 16 & - \\
\hline
\end{tabular}

a AP, anteroposterior; PA, posteroanterior; LAT, lateral.

${ }^{b}$ Last column indicates ESD values corresponding to diagnostic reference levels (DRLs) for pediatric patients from European Commission (7).

mean ESD values between 0.03 and 0.12 $\mathrm{mGy}$ for chest examinations (AP and PA projections), substantially lower than those observed in this study, probably because in that study only pediatric hospitals were considered. Besides chest examinations, we found no other ESD measured values to pediatric or adult patients in Brazil reported in the literature-only one paper has been published recently with ESD values for some pediatric examinations, calculated with a commercial software package (22).

The distribution of mean ESD values to pediatric and adult patients in the most frequent examinations and projections is shown in a box plot in Figure 3. All the distributions show maximum values very distant from the mean values. In some examinations, fluoroscopy was used (instead of the diaphragm light field) to localize the region to be radiographed. This incorrect and unneces- sary practice was also reported in the questionnaires by two radiological technicians, indicating that it is a routine practice. It is important to point out that a state regulation forbids the use of fluoroscopy in conventional x-ray examinations (23). An analysis of ESD to individual patients shows values up to 5 times higher, when fluoroscopy was used, reaching $50 \mathrm{mGy}$ in a LAT lumbar spine examination.

It was also possible to evaluate the correlation between the exposure parameters and individual ESDs in some examinations. The mean individual ESD and exposure setting (mAs) corresponding to each interval of tube potential $(\mathrm{kV})$ were calculated (Table 6), excluding examinations with informed use of fluoroscopy. The prevalent intervals of tube potential are not the ones that provide the lowest ESDs. In a comprehensive analysis, the increase of tube potential, followed by reduction of exposure setting, can be a very efficient means of reducing the ESD, in agreement with the results of the other studies $(6,21,24-26)$. Although this procedure could be important when the optimization principle is implemented, it must be utilized with careful criteria in the health services, as the diagnostic information contained in the radiological image might not be impaired with the reduction in doses. A study recently conducted in the United Kingdom shows that the isolated practice of raising the tube potential, without involvement of the technical and medical staff, can also lead to an increase in the doses to patients (27).

Adult patients. The ESD values in the third column of Table 4 (third quartile) correspond to values of DRLs to adult patients obtained in this work. A comparison of those values with the DRLs for adult patients supported by different recommendations is shown in Table 7 . DRLs for both cervical spine and sinus examinations are not provided by any of the recommendations, except the North American one.

In general, the DRLs obtained in this survey are lower than those from both national regulations of the Brazilian Ministry of Health (9) and international recommendations, except for some North American values. However, the corresponding values from both Portaria number 453 and Safety Series number 115 are for conventional film-screen combination (relative speed 200). For highspeed film-screen combinations (400600 ), the values should be reduced by a factor of 2 to 3 . Therefore, the DRL values obtained in this survey may indicate that film-screen combinations with speeds higher than 200 are being used. The great majority of health services did not supply this information, although it was requested. With regard to the few services that supplied the information, the filmscreen combinations point to a nominal speed of $400(27,28)$. If combinations with higher speeds are confirmed, the ESDs obtained here are above the recommended value, and a program to reduce ESDs in conventional radiological examinations in Brazil must be implemented, especially in São Paulo state. On the other hand, if a nominal speed of 200 is really being used, acceptance of more restricted DRLs in Brazil should be possi- 
FIGURE 3. Distribution of mean ESD values to pediatric and adult patients in the most frequent examinations and projections, ${ }^{a}$ Brazil, 2004
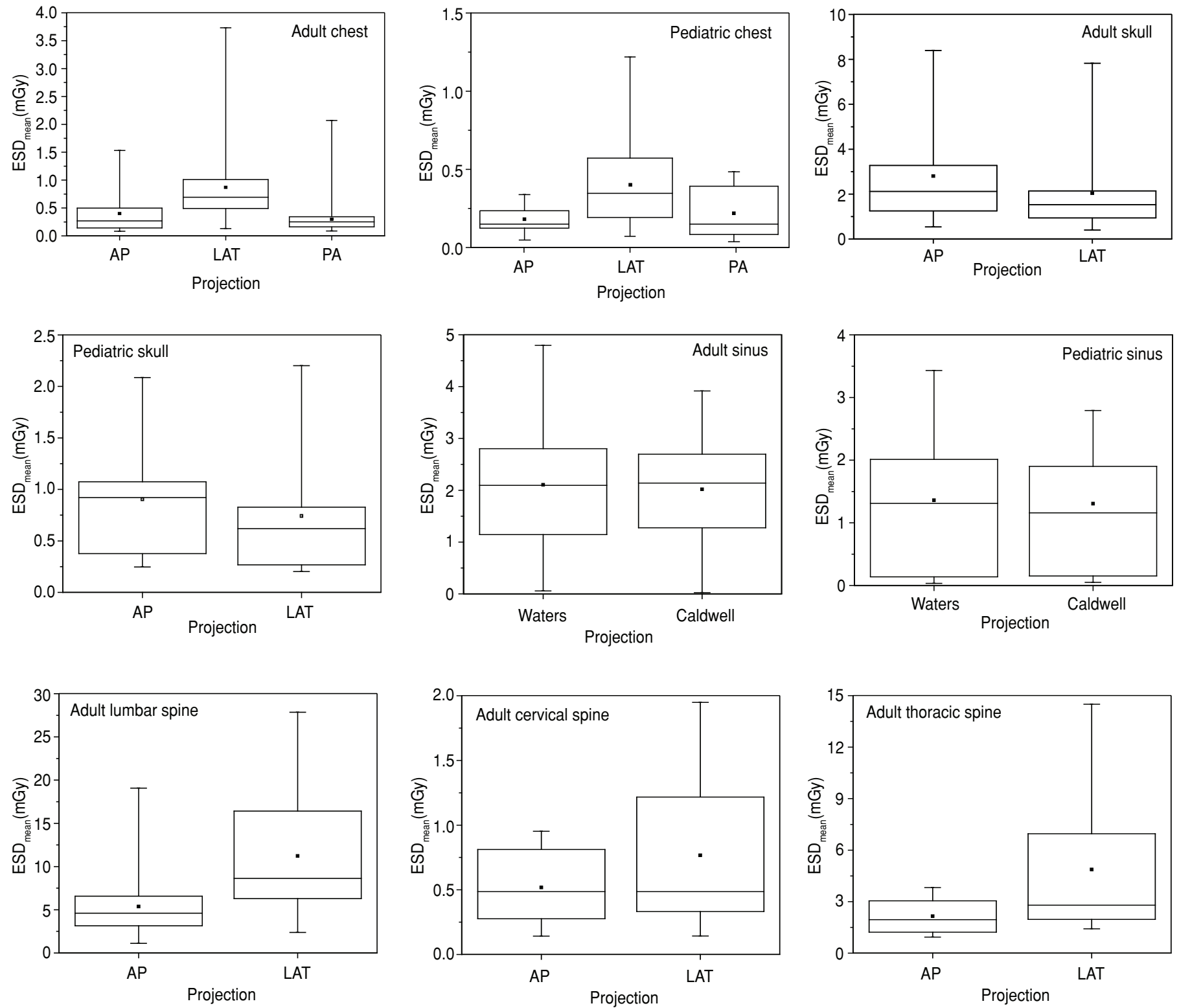

a Box plot graphs summarize the following statistical parameters: mean (square dot inside box), minimum and maximum values (extremities of vertical lines), 75th and 25th percentiles of data set (upper and lower edge of box, respectively), and median (50th percentile, horizontal line inside box).

ble. Local or regional DRLs have already been achieved in countries such as England, showing a great effect in reducing patient doses as part of the optimization program $(29,30)$.

Pediatric patients. The third quartile of the distribution of mean ESDs per room (third column in Table 5) corresponds to our suggestion of DRLs for pediatric patients subjected to chest or head examinations. As in Brazil, there is no recommendation for this group of patients; the outcomes provided in this survey, al- though for a small number of examinations and patients, are a consistent initiative in that direction. DRLs reported in international recommendations are derived from patients with a mean age of 5 years, with information that DRLs for patients with a mean age of 10 years are very similar. We consider that this assertion justifies the decision we made in considering the whole set of doses to patients under 15 years old as our pediatric sample.

The analysis of DRLs for pediatric patients shows that, unlike adult patients, there is a big divergence of the DRL values found in this survey and the international ones (7), shown also in Table 5 (sixth column): they are up to twice as large as the international recommendations for chest examinations of children. This fact points out that practices need to be revised and that specific recommendations for this patient group, following other more specific surveys, should be provided. However, DRLs for patients undergoing skull examinations are similar to those published in international recommendations. This outcome may be 
TABLE 6. Mean values of individual entrance surface doses (ESDs), exposure setting, and percentage of examinations corresponding to each interval of tube potential used in radiological examinations, Brazil, 2004

\begin{tabular}{|c|c|c|c|c|c|c|c|c|c|}
\hline Examination ${ }^{a}$ & $\begin{array}{c}\text { Interval } \\
\text { of tube } \\
\text { potential, kV }\end{array}$ & $\begin{array}{c}\text { Exposure } \\
\text { setting, } \\
\text { mAs }\end{array}$ & $\begin{array}{l}\text { ESD, } \\
\text { mGy }\end{array}$ & $\begin{array}{c}\text { Relative number } \\
\text { of examinations, } \\
\%\end{array}$ & Examination & $\begin{array}{c}\text { Interval } \\
\text { of tube } \\
\text { potential, kV }\end{array}$ & $\begin{array}{l}\text { Exposure } \\
\text { setting, } \\
\text { mAs }\end{array}$ & $\begin{array}{l}\text { ESD, } \\
\text { mGy }\end{array}$ & $\begin{array}{c}\text { Relative number } \\
\text { of examinations, } \\
\%\end{array}$ \\
\hline \multirow[t]{5}{*}{ PA chest } & $50-65$ & 21 & 0.33 & 17 & \multirow[t]{4}{*}{ LAT chest } & $76-85$ & 20 & 0.83 & 35 \\
\hline & $66-80$ & 12 & 0.30 & 55 & & $86-100$ & 16 & 0.62 & 29 \\
\hline & $81-95$ & 9 & 0.24 & 16 & & $101-125$ & 15 & 0.56 & 16 \\
\hline & $96-125$ & 4 & 0.19 & 12 & & $40-57$ & 125 & 1.82 & 22 \\
\hline & $52-64$ & 117 & 4.61 & 25 & \multirow[t]{3}{*}{ LAT skull } & $58-64$ & 91 & 1.55 & 45 \\
\hline \multirow[t]{3}{*}{ AP skull } & $65-70$ & 52 & 2.32 & 60 & & $65-70$ & 27 & 1.09 & 33 \\
\hline & $71-77$ & 27 & 1.68 & 15 & & $55-70$ & 293 & 14.29 & 17 \\
\hline & $52-65$ & 103 & 6.40 & 35 & \multirow{4}{*}{$\begin{array}{l}\text { LAT lumbar } \\
\text { spine }\end{array}$} & $71-80$ & 121 & 10.27 & 41 \\
\hline \multirow[t]{3}{*}{ AP lumbar spine } & $66-75$ & 81 & 4.87 & 44 & & $81-90$ & 134 & 10.23 & 31 \\
\hline & $76-96$ & 55 & 4.60 & 21 & & $91-125$ & 63 & 8.42 & 11 \\
\hline & $60-75$ & 25 & 0.88 & 20 & & & & & \\
\hline
\end{tabular}

${ }^{\mathrm{a} A P}$, anteroposterior; PA, posteroanterior; LAT, lateral.

the result of the reduced number of individual ESD values and rooms obtained for this kind of radiological examination associated with the main participation of health services specializing in pediatric patients for this group of values.

Variation in size and patient doses is most noticeable among children and the use of a single reference size, as suggested by the European Commission (7) and used in this study, remains a practical problem in large-scale dose surveys in this patient group. Some surveys indicate correction factors for ESDs mea- sured in pediatric patients as a means of determining the DRLs for different ages $(31,32)$. A recent survey carried out in Finland (33) reported a method that takes into account patient size when setting pediatric DRLs for chest x-ray examinations. Pediatric DRLs for conventional chest examinations have been specified as a DRL curve by using both dose quantities for ESD and dose-area product as a function of patient projection thickness. This graphic method seems to be ideal for setting DRLs when a sufficient number of patient dose mea-

TABLE 7. Values corresponding to third quartile of distribution of entrance surface dose (ESD) (mGy) obtained in this survey from standard-sized adult patients undergoing conventional radiological examinations compared with diagnostic reference levels from national and international recommendations, ${ }^{\mathrm{a}}$ Brazil, 2004

\begin{tabular}{lcccccccc}
\hline \multicolumn{1}{c}{ Examination $^{\mathrm{b}}$} & $\begin{array}{c}\text { This } \\
\text { survey }\end{array}$ & $\begin{array}{c}\text { Port. }^{\mathrm{c}} \\
\mathrm{n} \text {-453 }\end{array}$ & NRPB $^{\mathrm{d}}$ & AAPM $^{\mathrm{e}}$ & EC $^{\mathrm{f}}$ & IAEA $^{\mathrm{g}}$ & IPSM $^{\mathrm{h}}$ & CRCPD $^{\mathrm{i}}$ \\
\hline AP chest & 0.50 & $\ldots$ & $\ldots$ & $\ldots$ & $\ldots$ & $\ldots$ & $\ldots$ & $\ldots$ \\
PA chest & 0.35 & 0.40 & 0.30 & 0.25 & 0.30 & 0.40 & 0.30 & 0.20 \\
LAT chest & 0.96 & 1.50 & 1.50 & $\ldots$ & 1.50 & 1.50 & 1.50 & $\ldots$ \\
AP skull & 3.3 & 5.0 & 5.0 & $\ldots$ & 5.0 & 5.0 & 5.0 & $\ldots$ \\
LAT skull & 2.1 & 3.0 & 3.0 & $\ldots$ & 3.0 & 3.0 & 3.0 & 1.3 \\
Waters sinus & 2.8 & $\ldots$ & $\ldots$ & $\ldots$ & $\ldots$ & $\ldots$ & $\ldots$ & $\ldots$ \\
Caldwell sinus & 2.7 & $\ldots$ & $\ldots$ & $\ldots$ & $\ldots$ & $\ldots$ & $\ldots$ & $\ldots$ \\
AP lumbar spine & 6.6 & 10.0 & 10.0 & 5.0 & 10.0 & 10.0 & 10.0 & 3.9 \\
LAT lumbar spine & 16.2 & 30.0 & 30.0 & $\ldots$ & 30.0 & 30.0 & 30.0 & $\ldots$ \\
AP cervical spine & 0.72 & $\ldots$ & $\ldots$ & 1.25 & $\ldots$ & $\ldots$ & $\ldots$ & 1.20 \\
LAT cervical spine & 1.20 & $\ldots$ & $\ldots$ & $\ldots$ & $\ldots$ & $\ldots$ & $\ldots$ & $\ldots$ \\
AP thoracic spine & 2.9 & 7.0 & 7.0 & $\ldots$ & $\ldots$ & 7.0 & $\ldots$ & $\ldots$ \\
LAT thoracic spine & 6.2 & 20.0 & 20.0 & $\ldots$ & $\ldots$ & 20.0 & $\ldots$ & $\ldots$ \\
\hline
\end{tabular}

${ }^{a}$ Adapted from International Commission on Radiological Protection publication (34).

${ }^{b} \mathrm{AP}$, anteroposterior; PA, posteroanterior; LAT, lateral.

'Portaria number 453, Brazilian Ministry of Health (1998).

dNRPB, National Radiological Protection Board, United Kingdom (1999).

eAAPM, American Association of Physicists in Medicine task Group, United States of America (1999).

'EC, European Commission (1999)

gIAEA, International Atomic Energy Agency (1996).

hIPSM, Institute of Physical Sciences in Medicine, United Kingdom (1992).

iCRCPD, Conference of Radiation Control Program Directors, Inc., United States of America (1988).

j. .., not available.

surements are not easily available. Unfortunately, the patient projection thickness was not evaluated in this study and normally it is a difficult measurement in a large-scale dose survey.

\section{Conclusions}

The sampling of health services with statistical criteria (stratified sampling technique) made it possible to test a representative set of hospitals and clinics in São Paulo state for this study. Furthermore, the postal dosimetric kit, developed considering the national reality, allowed implementation of a large-scale survey of ESDs, which is a pioneer study in Brazil. Nonetheless, it remains necessary to make an effort to increase the involvement of the health services in this type of medical dosimetry survey.

Although the survey was concentrated in the state of São Paulo, both the diversity of the health services (public or private domain, size, levels of health care) and the systematic methodology for the ESD evaluation allow for the collected data to be extrapolated to the remainder of the country, as there is a lack of largescale dose surveys in Brazil.

The information collected on characteristics of patients undergoing conventional radiological examinations and exposure parameters $(\mathrm{kV}, \mathrm{mAs}$, and SID) used in the realization of these examinations has led to identification of the predominant age group for each type of examination. In addition, the behavior of individual ESDs under specific combinations of tube potential $(\mathrm{kV})$ and exposure setting (mAs) was analyzed. With this in mind, the increase in tube 
potential, followed by a reduction of the exposure setting, can be a very efficient means of reducing the ESD. The large variation in ESD values indicates that much can be done to decrease patient doses by changing parameters $(\mathrm{kV}$, mAs), without loss of image quality, pointing to the importance of quality control programs. It is important to guarantee that, in this process of dose optimization, the image quality be maintained or improved to prevent images of poor quality that do not provide diagnostic information. Although image quality was not directly evaluated in this study, all participant health services were requested to evaluate ESD exclusively associated with examinations that provide images with the clinical purposes required by the radiologist.

The ESD values associated with DRLs were determined in this study considering the national reality, unlike officially adopted values. DRLs obtained in this study for adult patients are, in general, lower than those from national regulations and international recommendations, but the speed film-screen combinations must be evaluated for better comparison. On the other hand, ESD val- ues to pediatric patients subjected to chest examinations point out that practices in this patient group need to be revised. Specific ESD surveys and recommendations, comprising other examinations, must be carried out. Establishment of national reference doses for this group of patients could be an important way to show special concern for their protection.

Acknowledgments. The authors thank the staff of all hospitals participating in the survey. Marcelo Freitas appreciates the support of FAPESP (00/01056-0) and E. M. Yoshimura of CNPq (301974/2006-3).

\section{REFERENCES}

1. Wall BF. Radiation protection dosimetry for diagnostic radiology patients. Radiat Prot Dosimetry. 2004;109(4):409-19.

2. Commission of the European Communities. Health protection of individuals against the dangers of ionizing radiation in relation to medical exposure and repealing Directive 84/466/Euratom. Council Directive 97/43/ Euratom. Official Journal of the European Communities, L180/22; 1997.

3. Wall BF, Shrimpton PC. The historical development of reference doses in diagnostic radiology. Radiat Prot Dosimetry. 1998;80(1-3): $15-20$.

4. International Commission on Radiological Protection. 1990 recommendations of the International Commission on Radiological Protection. ICRP Publication 60. Oxford: Elsevier; 1991. Ann ICRP. 1991:21(1-3).

5. International Commission on Radiological Protection. Radiological protection and safety in medicine. ICRP Publication 73. Oxford: Elsevier; 1996. Ann ICRP. 1996:26(2).

6. European Commission. European guidelines on quality criteria for diagnostic radiography images. Report EUR 16260EN. Luxembourg: Office for Official Publications of the European Communities; 1996.

7. European Commission. European guidelines on quality criteria for diagnostic radiography images in paediatrics. Report EUR 16261EN. Luxembourg: Office for Official Publications of the European Communities; 1996.

8. European Commission, CT Study Group. European guidelines on quality criteria for computed tomography. Report EUR 16262. Luxembourg: Office for Official Publications of European Communities; 1999.

9. Secretaria de Vigilância Sanitária do Ministério da Saúde. Diretrizes Básicas de Proteção Radiológica em Radiodiagnóstico Médico e Odontológico. Portaria $\mathrm{n}^{\circ} 453$. Diário Oficial da União; 1998.

10. Food and Agriculture Organization of the United Nations, International Atomic Energy Agency, International Labor Organization, Nuclear Agency of the Organization for Economic Co-operation and Development,
Pan American Health Organization, World Health Organization. International basic safety standards for protection against ionizing radiation and for the safety of radiation sources. Safety series 115 . Vienna: IAEA; 1996.

11. Cochran WG. Sampling techniques. 3rd ed. New York: John Wiley \& Sons; 1977.

12. Cadastro Nacional dos Estabelecimentos de Saúde, CNES/Secretaria de Assistência à Saúde do Ministério da Saúde. Available from: http://cnes.datasus.gov.br. Accessed September 2004.

13. Freitas MB, Yoshimura EM. Levantamento da distribuição de equipamentos de diagnóstico por imagem e da freqüência de exames radiológicos no estado de São Paulo. Radiol Bras. 2005;38(5):347-54.

14. Freitas MB, Yoshimura EM. Dose measurements in chest diagnostic $X$ rays: adult and paediatric patients. Radiat Prot Dosimetry. 2004;111(1):73-6.

15. National Radiological Protection Board. National protocol for patient dose measurements in diagnostic radiology. Dosimetry Working Party of the Institute of Physical Sciences in Medicine. Chilton, United Kingdom: NRPB; 1992.

16. Shrimpton PC, Wall BF, Jones DG, Fisher ES, Hillier MC, Kendall GM, et al. Doses to patients from routine diagnostic $\mathrm{X}$ ray examinations in England. Br J Radiol. 1986;59:749-58.

17. National Radiological Protection Board. Doses to patients from medical x-ray examinations in the UK-1995 review. Chilton, United Kingdom: NRPB; 1996. Doc. NRPBR289.

18. Oliveira ML, Khoury H. Influência do procedimento radiográfico na dose de entrada na pele de pacientes em raios $X$ pediátricos. Radiol Bras. 2003;36(2):105-9.

19. Mohamadain KEM, da Rosa LAR, Azevedo ACP, Guebel MRN, Boechat MCB, Habani F. Dose evaluation for paediatric chest $\mathrm{x}$-ray examinations in Brazil and Sudan: low doses and reliable examinations can be achieved in developing countries. Phys Med Biol. 2004;49: 1017-31.
20. Tilly Jr, JG. Avaliação de doses de radiação em pacientes submetidos a exames radiológicos convencionais. Master's thesis. Faculdade de Filosofia, Ciências e Letras de Ribeirão Preto da Universidade de São Paulo; 1997.

21. Freitas MB, Yoshimura EM. An overview of doses to patients and irradiation conditions of diagnostic chest X-ray examinations carried out in hospitals of the city of São Paulo, Brazil. Radiat Prot Dosimetry. 2003;103(2): 141-8.

22. Azevedo $\mathrm{ACP}$, Osibote $\mathrm{OA}$, Boechat $\mathrm{MCB}$. Paediatric x-ray examinations in Rio de Janeiro. Phys Med Biol. 2006;51:3723-32.

23. Secretaria de Estado de Saúde. Norma técnica que dispõe sobre o uso, posse e armazenamento de fontes de radiação ionizante, no âmbito do Estado de São Paulo. 1994. Resolução SS-625.

24. Martin CJ, Darragh CL, McKenzie GA, Bayliss AP. Implementation of a programme for reduction of radiographic doses and results achieved through increases in tube potential. Br J Radiol. 1993;66:228-33.

25. Ortiz P, Maccia C, Padovani R, Vañó E, Carlsson GA, Schibilla H. Results of the IAEA-CEC coordinated research programme on radiation doses in diagnostic radiology and methods for reduction. Radiat Prot Dosimetry. 1995;57(1-4):95-9.

26. Mooney R, Thomas PS. Dose reduction in a paediatric $x$-ray department following optimization of radiographic technique. Br J Radiol. 1998;71:852-60.

27. Hart D, Hillier MC, Wall BF, eds. Doses to patients from medical $\mathrm{X}$-ray examinations in the UK-2000 review. Chilton, United Kingdom: National Radiological Protection Board; 2002. Doc. NRPB-W14.

28. Wolbarst AB. Physics of radiology. Norwalk, Connecticut: Appleton \& Lange; 1993.

29. Wright DJ, Ramsdale ML. The use of national and locally set reference dose levels in a regional programme for dose reduction in diagnostic radiology. Radiat Prot Dosimetry. 1998;80(1-3):103-7.

30. Connolly P, Moores BM. Establishing local reference dose values and optimization 
strategies. Radiat Prot Dosimetry. 2000;90(1-2): $229-34$.

31. Hart D, Wall BF, Shrimpton PC, Dance DR. The establishment of reference doses in paediatric radiology as a function of patient size. Radiat Prot Dosimetry. 2000;90(1-2):235-8.

32. Schneider K, Kohn MM, Ernest G. The derivation of reference dose values to chest $x$ rays in paediatric radiography. Radiat Prot Dosimetry. 1998;80(1-3):199-202.

33. Kiljunen $T$, Järvinen $H$, Savolainen S. Diagnostic reference levels for thorax $\mathrm{x}$-ray examinations of paediatric patients. Br J Radiol. 2007;80:452-9.

34. International Commission on Radiological Protection. Diagnostic reference levels in med- ical imaging: review and additional advice. Oxford, United Kingdom: Elsevier; 2001. Ann ICRP. 2001;31(4):33-52.

Manuscript received on 26 September 2007. Revised version accepted for publication on 2 April 2008

RESUMEN Objetivos. Estudio a gran escala de las dosis aplicadas a pacientes sometidos a los exámenes radiológicos más frecuentes realizados en los servicios de salud de São Paulo (347 exámenes radiológicos por 1000 habitantes), el estado más poblado de

Niveles de referencia diagnósticos para los exámenes radiológicos más frecuentes realizados en Brasil

\section{Brasil.}

Métodos. Se empleó un sistema dosimétrico postal con dosímetros termoluminiscentes para evaluar la dosis en la superficie de entrada (DSE) de los pacientes. Se realizó un muestreo estratificado de la base de datos nacional de salud que aportó información importante sobre la distribución del equipamiento y el número de pruebas realizadas anualmente. El estudio abarcó los exámenes de tórax, cabeza (cráneo y senos paranasales) y columna vertebral (cervical, dorsal y lumbar). Se incluyeron 83 instalaciones y 868 pacientes; se obtuvieron 1415 mediciones de DSE.

Resultados. Los resultados mostraron grandes coeficientes de variación en la carga del tubo, lo que originó variaciones considerables en las DSE. Además, se detectaron valores elevados de DSE asociados con fluoroscopias de localización innecesarias. Los niveles de referencia diagnósticos se determinaron a partir del percentil 75 (tres cuartiles) de las distribuciones de las DSE. Para pacientes adultos, los niveles de referencia diagnósticos alcanzados fueron muy similares a los obtenidos en estudios internacionales. No obstante, la situación fue diferente en los pacientes pediátricos: los valores de DSE obtenidos en este estudio fueron dos veces mayores que los recomendados internacionalmente para radiografías de tórax en niños.

Conclusiones. A pesar del reducido número de valores de DSE e instalaciones en el grupo de pacientes pediátricos, se recomienda revisar la práctica de estudios radiológicos de tórax y establecer referencias nacionales específicas para las dosis y la calidad de las imágenes, después de realizar un estudio más amplio.

Palabras clave Dosimetría termoluminiscente, radiología, Brasil. 